\title{
Validation of an HPLC assay for determination of Telazol in pregnant pigs: application to placental transfer study
}

\author{
Wei LI')\#, Gangshi LI'1) , Zhijun ZHONG ${ }^{1) \#, ~ B i n g b i n g ~ X I E ' 1), ~ Z i y a o ~ Z H O U 1), ~}$ \\ Wuyang $\mathrm{GU}^{1}{ }^{1}$, Xianpeng $\mathrm{SHI}^{1}$ ), Tianliang $\mathrm{TANG}^{1}{ }^{1}$, Shengquan $\mathrm{Al}^{1}$ ), \\ Hualin FU ${ }^{1)}$,Mengjiao LIU1), Mengxi LIU 1), De WU ${ }^{2)}$, Yanchun $\mathrm{HU}^{1)}$ and \\ Guangneng PENG ${ }^{1) *}$ \\ ${ }^{1)}$ Key Laboratory of Animal Disease and Human Health of Sichuan Province, College of Veterinary Medicine, \\ Sichuan Agricultural University, Ya'an 625014, P. R. China \\ 2)Institute of Animal Nutrition, Sichuan Agricultural University, Ya'an 625014, P. R. China
}

J. Vet. Med. Sci.

79(4): 801-806, 2017

doi: 10.1292/jvms.16-0300

Received: 22 June 2016

Accepted: 23 February 2017

Published online in J-STAGE:

7 March 2017
ABSTRACT. Anesthetics utilized for the immobilization of pregnant mammals are prone to crossing the placental barrier and cause adverse effects to the fetuses. In this study, we develop a facile method employing high performance liquid chromatography (HPLC) for the study of Telazol crossing the placental barrier of pregnant pigs. The method mainly relies on the efficient extraction strategy that includes the mobile phase composed of $10 \mathrm{mM}$ ammonium acetate aqueous solution-acetonitrile $(1: 4, \mathrm{v} / \mathrm{v})$. When the injected dose of Telazol is $10 \mathrm{mg} / \mathrm{kg}(5 \mathrm{mg} / \mathrm{kg}$ of each constituent drug, zolazepem and tiletamine), zolazepam can cross the placental barrier as it is detected in both uterus and umbilical cord with approximately the same content. Conversely, tiletamine is detected in neither uterus nor umbilical cord, indicating the absence of placental transfer of tiletamine. The different absorption rates of the two dosage-equal compounds by pigs are found to be the main cause of their different abilities to cross the placental barrier.

KEY WORDS: HPLC, placental barrier, pregnant pigs, tiletamine, zolazepam

Pregnant mammals are frequent subjects of veterinary surgeries, where varieties of anesthetics are adopted to immobilize them $[1,6,9]$. In the past years, extensive efforts have been made to study the metabolism and immobilizing effect of anesthetics $[2,4,8]$. However, apart from the role of tranquillizer, many anesthetics are prone to cross the placental barrier of pregnant mammals and thereby cause adverse effects to the pregnancy. For example, Telazol (an equal weight combination of tiletamine and zolazepam) was found to cross the placental barrier of pregnant dogs and produce respiratory depression in the newborn puppies [17]. In addition, ewes were found to suffer the similar situation when anesthetized by etomidate [5]. These findings have stimulated much concerns in the anesthesia of gestational mammals. Therefore, it's imperative to develop an effective method to study the placental transfer of drugs. Theoretically, once a drug penetrates the placental barrier, it will enter the fetuses by way of the umbilical cord. From this point of view, the detection of anesthetic residues in uterus and umbilical cord is beneficial for the diagnosis of drugs' placental transportation. In recent years, the rapid development of liquid chromatography (LC) and gas chromatography (GC) has enabled huge progress in the pharmacokinetics study of anesthetics due to the high sensitivity of these techniques $[3,7,12,15]$. However, the application of LC or GC in the placental transfer of Telazol was barely reported. In the present study, we report the development and validation of a facile method employing high performance liquid chromatography (HPLC) for the study of placental transfer of tiletamine and zolazepam in pregnant mammals.

\section{MATERIALS AND METHODS}

\section{Animals}

This experiment proceeded under the permission and supervision of Institutional Animal Care and Use Committee in College of Animal Science and Technology, Sichuan Agricultural University, Sichuan, China (permit No.DKY-B20100805). Four Meishan female pigs with mean bodyweight of $190.9 \mathrm{~kg}$ were fertilized at the same day. All pigs were obtained from the Institute of Animal

*Correspondence to: Peng, G., Key Laboratory of Animal Disease and Human Health of Sichuan Province, College of Veterinary Medicine, Sichuan Agricultural University, Ya'an 625014, P. R. China. e-mail: pgn.sicau@163.com

\#These authors contributed equally to this work.

(02017 The Japanese Society of Veterinary Science

This is an open-access article distributed under the terms of the Creative Commons Attribution Non-Commercial No Derivatives (by-ncnd) License. (CC-BY-NC-ND 4.0: https://creativecommons.org/licenses/by-nc-nd/4.0/) 
Nutrition of Sichuan Agricultural University. The animals were put in a quiet room at the 76 days of pregnancy to avoid any stress-inducing factors. The study was conducted after raising the pigs in the isolated room for 14 days, during which wheat-based diet was fed to the pigs to any metabolic variations or stress. The feeding standard is in consistence with the previous report [10]. Prior to the cesarean section, all pigs were fasted for $24 \mathrm{hr}$, and water was withheld for $2 \mathrm{hr}$ before anesthesia to get rid of any side effects, such as vomiting during the anesthesia or recovery period. No adult pigs died during the research, while all newborns died shortly after the surgery because of the prematurity.

\section{Chemicals}

Tiletamine and zolazepam were both obtained from Sigma-Aldrich (Rockville, MD, U.S.A.); Medazolam (internal standard, IS) and acetonitrile were purchased from Sigma-Aldrich (St. Louis, MO, U.S.A.).

\section{Preparation of samples for calibration curve}

One $\mathrm{mg} / \mathrm{ml}$ of both tiletamine hydrochloride and zolazepam hydrochloride in acetonitrile were prepared as stock solutions, followed by dilution with mobile phase (10 mM ammonium acetate aqueous solution-acetonitrile, 1:4, v/v) to yield working solutions $(0.5,2.5,25,50,100,250,500$ and $1,250 \mu \mathrm{g} / \mathrm{m} l$ for tiletamine and 2.5, 25, 50, 125, 250, 500, 1,250 and 2,500 $\mu \mathrm{g} / \mathrm{m} l$ for zolazepam). To obtain calibrations for both drugs, $5 \mu l$ of each working solution was spiked with the pig plasma (245 $\mu l$ ), resulting in effective plasma concentrations in the range of $0.01-25 \mu \mathrm{g} / \mathrm{m} l$ for tiletamine and $0.05-50 \mu \mathrm{g} / \mathrm{m} l$ for zolazepam. Calibration curves for both drugs were obtained by plotting the ratio between areas under the peak of each compound and the IS (1.5 $\mu \mathrm{g} / \mathrm{m} l)$ against the corresponding analyte concentrations.

\section{Preparation of samples for quality control}

Quality control samples were prepared by spiking $225 \mu \mathrm{l}$ of pig plasma with $25 \mu \mathrm{l}$ of serially diluted solutions of each drug, resulting in the lower limit of quantification $(0.01$ and $0.05 \mu \mathrm{g} / \mathrm{m} l)$, low $(0.1$ and $0.5 \mu \mathrm{g} / \mathrm{m} l)$, intermediate $(2.5$ and $5 \mu \mathrm{g} / \mathrm{m} l)$ and high concentrations $(25$ and $40 \mu \mathrm{g} / \mathrm{m} l)$ of control samples for tiletamine and zolazepam, respectively.

\section{Sample extraction}

For both validation, $300 \mu l$ of the IS $(2.5 \mu \mathrm{g} / \mathrm{m} l$ in acetonitrile) was added to $200 \mu l$ of each quality control sample, vortexed for $1 \mathrm{~min}$ and centrifuged for $10 \mathrm{~min}(10,000 \mathrm{rpm})$. Then, $20 \mu \mathrm{l}$ of the extraction was injected into the column. The same experiment was conducted for the determination of tiletamine and zolazepam in pigs' plasma, uterus and umbilical cord after intramuscular administration.

\section{Method validation}

The validation procedure was mainly concentrated on extraction recovery, precision and accuracy. The between-days and withinday precision and accuracy of the method were evaluated by employing the calibration curves to predict the concentration of the quality control samples. In principle, the results are reliable only when the precision and accuracy are within $15 \%$, which is $20 \%$ for lower of quantification as an exception.

\section{Stability analysis}

The stability of tiletamine and zolazepam was tested in plasma samples under different conditions. For both drugs, concentrations of control samples were determined to be 2.5 and $25 \mu \mathrm{g} / \mathrm{m} l$. The stability of all samples was examined after aging in room temperature for $8 \mathrm{hr}$ and $24 \mathrm{hr}$. In addition, the stability of all samples after three freeze-thaw cycles was also assessed. Generally, the analyte is defined to be stable only when the difference between the mean concentrations of tested samples under various conditions is within $\pm 15 \%$.

\section{Sampling process}

Plasma samples in pigs were collected by phlebotomizing at 10, 30, 60, 90, 120, 150,180, 210 and 240 min after the intramuscular injection of Telazol. Samples of uterus were collected at the centers of uterine subplacental area of a randomly selected utero-placental unit, while samples of umbilical cord were obtained from the fetus of the same unit phlebotomizing at $\sim 1 \mathrm{~cm}$ away from the fetal side. Specifically, as shown in Fig. 1, one of the fetuses was selected for the collection of the umbilical cord sample. Correspondingly, significant vascular proliferation will appear at the utero-placental unit. In this way, thin blood vessels assemble to form a much thicker vessel. In our experiment, the uterine sample was collected from the relatively thick vessel, considering that the thinner vessels cannot provide sufficient blood for characterization. All tissue samples were collected at 30, 40, 50 and $60 \mathrm{~min}$ after the intramuscular administration. For each sampling process, the blood volume was $4 \mathrm{ml}$. The heart rates of all pigs were monitored by ECG throughout the surgical procedure.

\section{Analysis system}

High performance liquid chromatography (HPLC) was employed to simultaneously detect tiletamine and zolazepam. The compounds were separated on a reversed-phase column (LC-2010C) in the mobile phase, eluted at $0.2 \mathrm{ml} / \mathrm{min}$ using a HP1100 series pump (Agilent, Wilmington, DE, U.S.A.) and monitored with an ultraviolet detector at $233 \mathrm{~nm}$. Twenty $\mu l$ of samples were injected using a Model SIL-9A autoinjector (Shimadzu Corp., Kyoto, Japan), and the quantification was performed by recording 


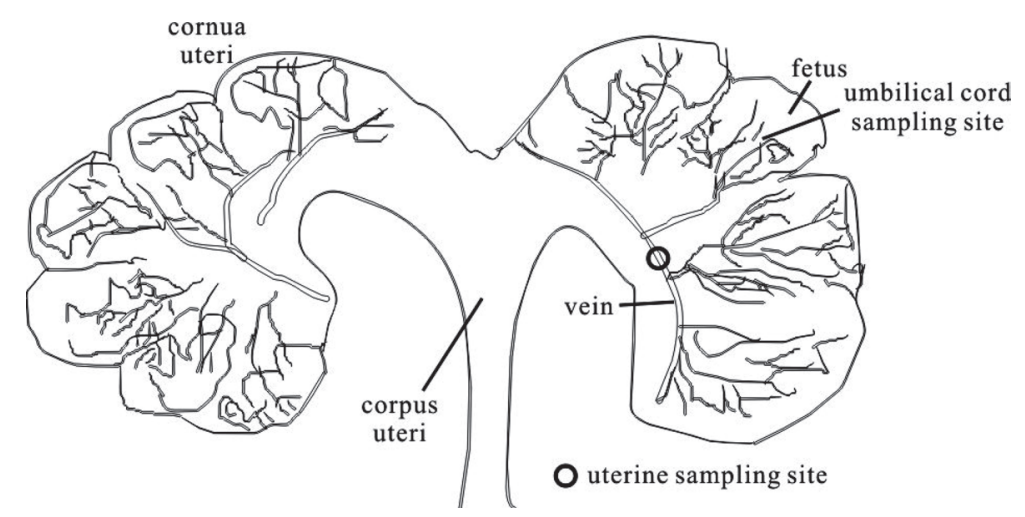

Fig. 1. Details of sampling sites of uterine samples.
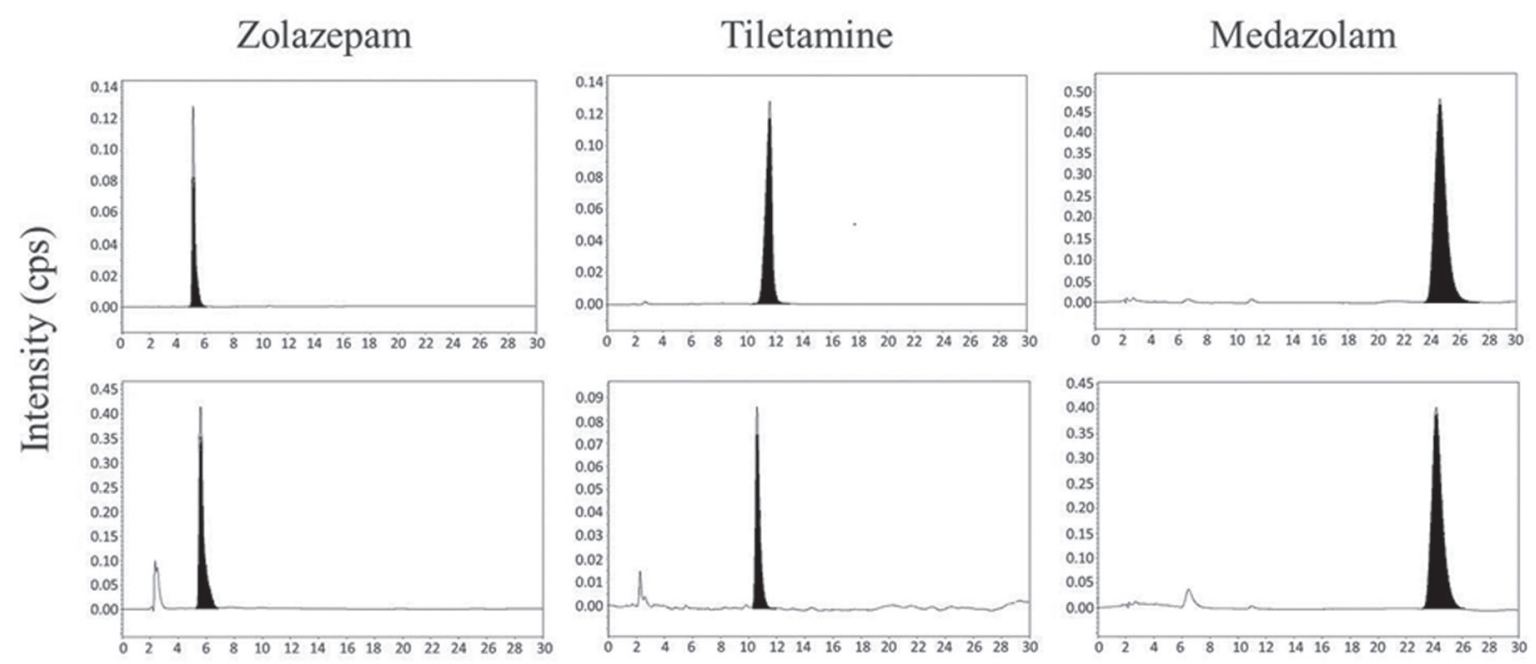

Time (min)

Fig. 2. Chromatograms of tiletamine, zolazepam and midazolam. Top panel: plasma sample spiked with $1 \mu \mathrm{g} / \mathrm{m} l$ tiletamine, $1 \mu \mathrm{g} / \mathrm{m} l$ zolazepam and $2.5 \mu \mathrm{g} / \mathrm{m} l$ medazolam; bottom panel: a plasma sample equivalent to $0.4 \mu \mathrm{g} / \mathrm{m} l$ for tiletamine, $3 \mu \mathrm{g} /$ $\mathrm{m} l$ for zolazepam and $2.5 \mu \mathrm{g} / \mathrm{m} l$ for midazolam, respectively, in a sample obtained from a pig at 30 min after the intramuscular administration of $10 \mathrm{mg} / \mathrm{kg}$ Telazol.

the peak area for each solution, and the peak ratios of analytes to internal standards were used to back-calculate the concentrations of analytes employing the standard curves.

\section{RESULTS}

Figure 2 presents represent chromatograms of zolazepam, tiletamine and midazolam (IS). The characteristic peaks of zolazepam, tiletamine and midazolam (IS) occur at 5.85, 11.85 and $24.92 \mathrm{~min}$, separately, for the simulated sample prepared by spiking the pig plasma with $10 \mathrm{ng} / \mathrm{m} l$ of tiletamine and $50 \mathrm{ng} / \mathrm{ml}$ of zolazepam. Similar signals for the plasma collected from pigs after intramuscular administration of Telazol appear at 5.89, 11.68 and 24.92 min corresponding to zolazepam, tiletamine and medazolam, respectively, indicating remarkable consistence with the simulated sample and thus the exact response to all drugs in our system. The calibration curves provide reliable responses for tiletamine and zolazepam $\left(\mathrm{R}^{2}>0.995\right)$. The ratios of the peak area of both compounds relative to that of the IS are correlated with the corresponding plasma concentrations, and good linearity was observed (Fig. 3).

The limits of quantification (LOQ) for tiletamine and zolazepam are set to be $10 \mathrm{ng} / \mathrm{ml}$ and $50 \mathrm{ng} / \mathrm{ml}$, respectively. Table 1 shows the extraction recoveries of tiletamine and zolazepam in pig plasma. It can be seen that the extraction recoveries are over $85 \%$ for both drugs. The between-days and within-day accuracy of tiletamine are $97.1-101.1 \%$ and $96.9-100.4 \%$, respectively, while those are $96.3-105.4 \%$ and $96.1-100.3 \%$ for zolazepam. The intra- and inter-day assay variability calculated from 5 parallel tests are all below $5 \%$ (Table 2). 

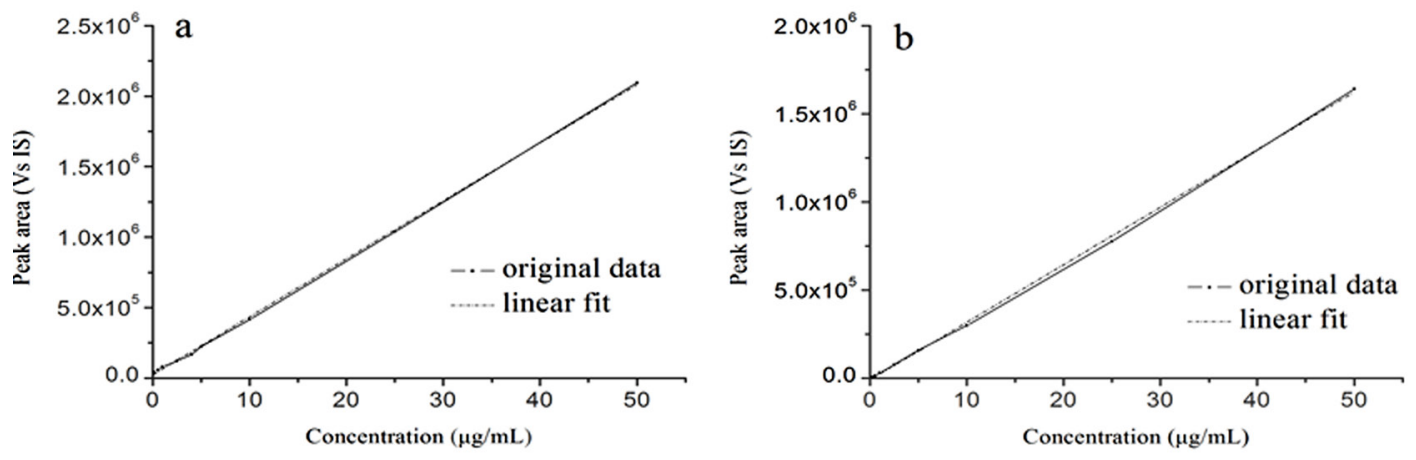

Fig. 3. Standard curves of (a) tiletamine and (b) zolazepam. Calibration curves for both drugs were obtained by plotting the ratio between areas under the peak of each compound and the IS $(2.5 \mu \mathrm{g} / \mathrm{m} l)$ against the corresponding analyte concentrations. The plotting concentrations are in the range of $10 n \mathrm{~g} / \mathrm{m} l \sim 50 \mu \mathrm{g} / \mathrm{ml}$ and $50 \mathrm{ng} / \mathrm{m} l \sim 50 \mu \mathrm{g} / \mathrm{ml}$ corresponding to tiletamine and zolazepam, respectively.

Table 1. Extraction recoveries of tiletamine and zolazepam from pig plasma

\begin{tabular}{cccc}
\hline Concentration $(\mu \mathrm{g} / \mathrm{m} l)$ & Tiletamine & Concentration $(\mu \mathrm{g} / \mathrm{m} l)$ & Zolazepem \\
\hline 0.1 & $98.9 \pm 2.9$ & 0.5 & $91.0 \pm 4.7$ \\
2.5 & $92.1 \pm 2.2$ & 5 & $86.9 \pm 4.2$ \\
25 & $89.7 \pm 2.2$ & 40 & $86.1 \pm 3.9$ \\
\hline
\end{tabular}

mean percentage $\pm \mathrm{SD}, \mathrm{n}=5$.

Table 2. Precision and accuracy of the intra-day and inter-day assay

\begin{tabular}{|c|c|c|c|c|c|}
\hline \multirow{2}{*}{$\begin{array}{l}\text { Concentration } \\
\qquad(\mu \mathrm{g} / \mathrm{m} l)\end{array}$} & \multicolumn{2}{|c|}{ Tiletamine } & \multirow{2}{*}{$\begin{array}{l}\text { Concentration } \\
\qquad(\mu \mathrm{g} / \mathrm{m} l)\end{array}$} & \multicolumn{2}{|c|}{ Zolazepam } \\
\hline & Intra-day & Inter-day & & Intra-day & Inter-day \\
\hline 0.01 & $99.6 \pm 2.2(2.2)$ & $98.1 \pm 3.6(3.7)$ & 0.05 & $101.7 \pm 4.5(4.4)$ & $98.6 \pm 2.1(2.1)$ \\
\hline 0.1 & $100.3 \pm 3.2(3.2)$ & $96.9 \pm 3.2(3.3)$ & 0.5 & $105.4 \pm 2.4(2.2)$ & $98.7 \pm 3.3(3.3)$ \\
\hline 2.5 & $97.1 \pm 3.0(3.1)$ & $100.4 \pm 3.9(3.9)$ & 5 & $98.1 \pm 3.8(3.9)$ & $100.3 \pm 3.2(3.2)$ \\
\hline 25 & $101.1 \pm 2.6(2.5)$ & $98.9 \pm 2.9(2.9)$ & 40 & $96.3 \pm 5.1(5.3)$ & $96.1 \pm 3.2(3.3)$ \\
\hline
\end{tabular}

mean percentage \pm SD (RSD), $n=5$.

Table 3. Stability of tiletamine and zolazepam under different storage conditions

\begin{tabular}{lrrrr}
\hline \multirow{2}{*}{ Condition } & \multicolumn{2}{c}{ Tiletamine } & \multicolumn{2}{c}{ Zolazepam } \\
\cline { 2 - 5 } & $2.5 \mu \mathrm{g} / \mathrm{m} l$ & $25 \mu \mathrm{g} / \mathrm{m} l$ & $2.5 \mu \mathrm{g} / \mathrm{m} l$ & $25 \mu \mathrm{g} / \mathrm{m} l$ \\
\hline Room temperature $(8 \mathrm{hr})$ & $97.9 \pm 2.9$ & $93.7 \pm 4.7$ & $101.8 \pm 4.4$ & $102.0 \pm 3.6$ \\
Room temperature $(24 \mathrm{hr})$ & $98.8 \pm 1.3$ & $96.1 \pm 2.3$ & $94.5 \pm 3.6$ & $98.4 \pm 2.2$ \\
3 cycles of freezing-thawing & $103.2 \pm 3.1$ & $101.3 \pm 4.3$ & $103.7 \pm 3.8$ & $90.1 \pm 1.9$ \\
$-20^{\circ} \mathrm{C}$ (30 days) & $95.3 \pm 3.9$ & $100.7 \pm 4.2$ & $92.9 \pm 5.0$ & $96.5 \pm 3.3$ \\
\hline
\end{tabular}

mean percentage $\pm \mathrm{SD}, \mathrm{n}=3$.

Table 3 shows the great stability of tiletamine and zolazepam under different conditions $(\mathrm{SD}<15 \%)$. Both tiletamine and zolazepam in plasma were stable up to $24 \mathrm{hr}$ at room temperature; they also remained intact at $-20^{\circ} \mathrm{C}$ for up to 30 days. No degradation was observed after three cycles of freezing and thawing.

Four Meishan pigs undergoing the cesarean section were selected for the content evaluation of tiletamine and zolazepam in uterus and umbilical cord, sampled by phlebotomizing from the center of exposed tissues after intramuscular administration of $10 \mathrm{mg} / \mathrm{kg}$ of Telazol. For comparison, drugs in plasma were also examined. Considering the operative duration, samples of uterus and umbilical cord were collected at 30-60 min after the infusion of Telazol. Figure 4 illustrates the content of tiletamine and zolazepam in four pigs' uterus, umbilical cord and plasma. As can be observed, zolazepam in plasma is around $1.0-1.1 \mu \mathrm{g} / \mathrm{m} l$ for all pigs, right in the plotting scope of the standard curve. The content of zolazepam in uterus and umbilical cord is at a steady level of about $1 \mu \mathrm{g} / \mathrm{ml}$ in the time range of 30-60 min, a bit lower than that in plasma. A notable fact is that no tiletamine was detected in uterus and umbilical cord, which prompted us to study the metabolism of tiletamine and zolazepam in pigs. 

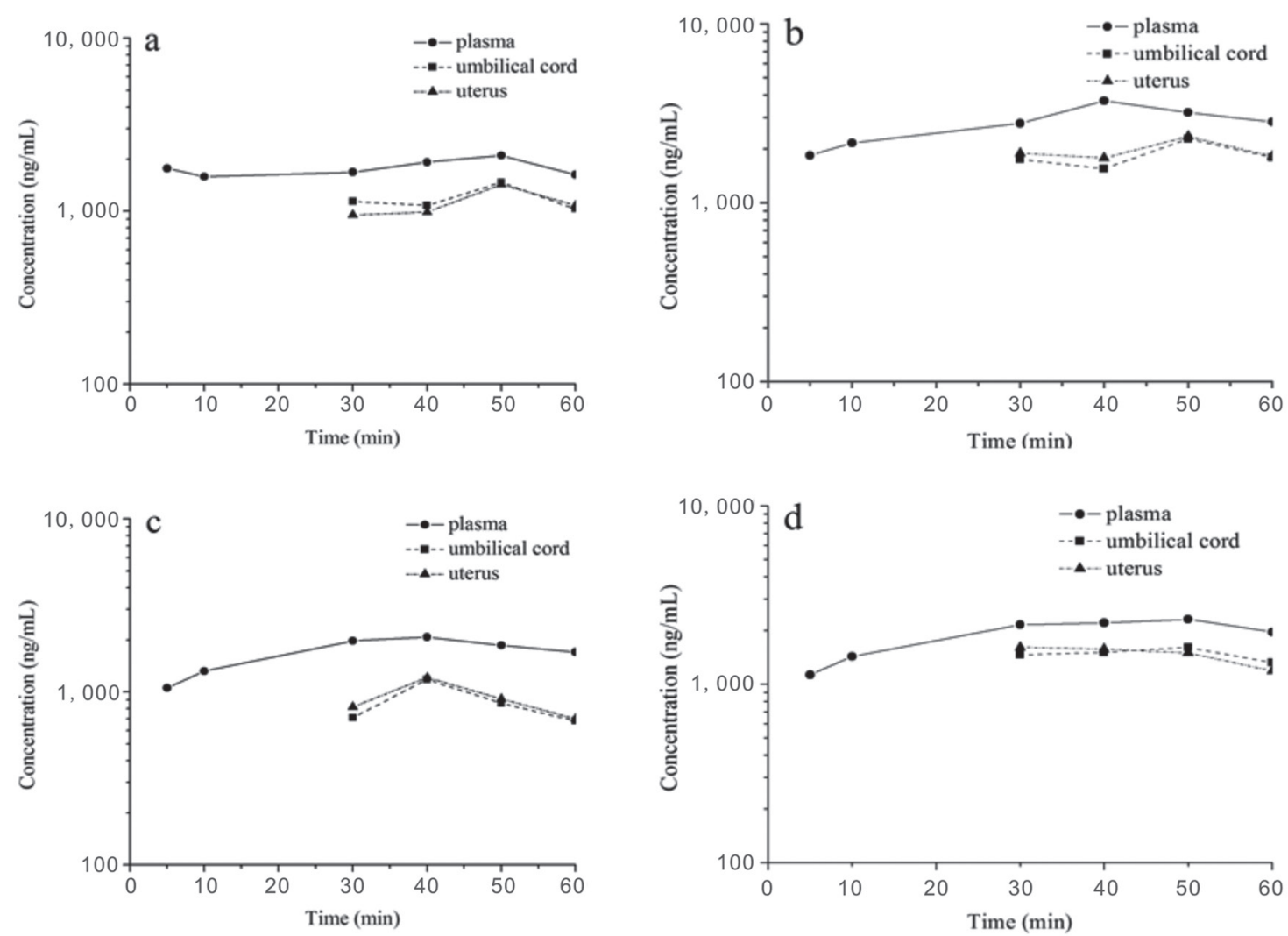

Fig. 4. Concentration-time profiles of zolazepam in plasma, uterus and umbilical cord in four anesthetized pigs after intramuscular administration of $10 \mathrm{mg} / \mathrm{kg}$ of Telazol.
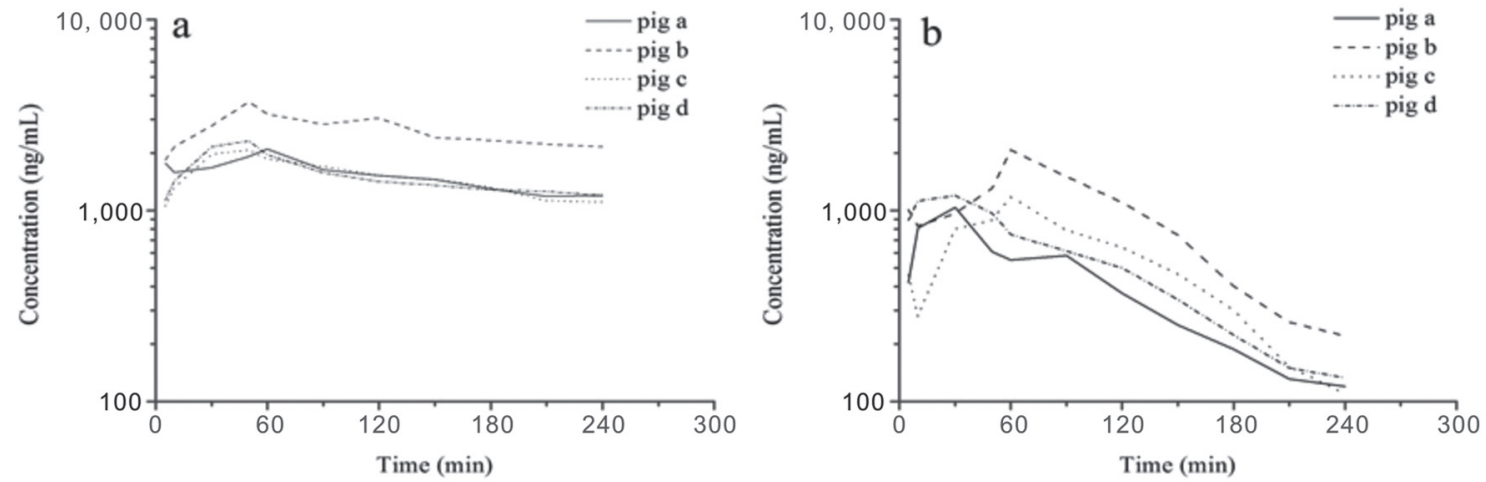

Fig. 5. Plasma concentration-time profiles of zolazepam (a) and tiletamine (b) in four pigs after intramuscular administration of $10 \mathrm{mg} / \mathrm{kg}$ of Telazol. Plasma samples were collected at interval times in the range of 10-240 min post administration.

By analyzing plasma samples collected at intervals from 5 to 240 min after intramuscular administration of Telazol, we found that the peak concentrations appeared at 50-60 min for both tiletamine and zolazepam (Fig. 5). Thereafter, the content of zolazepam gradually declines to about $50 \%$ the peak value in $4 \mathrm{hr}$ (Fig. 5a). As a sharp contrast to the slow elimination of zolazepam, tiletamine diminishes dramatically fast. As demonstrated in Fig. 5b, the content of tiletamine is only about $10 \%$ the peak value at 240 min after intramuscular administration.

\section{DISCUSSION}

In our work, the HPLC assay was employed to evaluate placental transfer of tiletamine and zolazepam. Generally, umbilical 
cord is the unique path for drugs in uterus to enter the fetus. Hence, the appearance of zolazepam in umbilical cord makes it reasonable for us to draw a conclusion that zolazepam in the pregnant pig can easily pass through the placental barrier when the injected dose is $5 \mathrm{mg} / \mathrm{kg}$. On the contrary, the absence of tiletamine in uterus and umbilical cord suggests that no tiletamine is transferred to the fetus through the placental barrier. The metabolism study indicates that tiletamine diminishes much quicker than zolazepam in pig plasma. Considering the great stability of tiletamine and zolazepam under different conditions, the difference in plasma concentrations is attributed to different absorption rates of tiletamine and zolazepam in pigs. To our knowledge, the placental drug transfer is dominated by passive diffusion $[13,14,16]$. Smaller molecules tend to take the passive diffusion more easily. From this point of view, due to its lower molecule weight (259.79), tiletamine can penetrate the placental barrier more easily compared with zolazepam (322.7651). However, only zolazepam was found to cross the placental barrier in our experiment. Accordingly, as dictated by Fick's first law, the penetrability of drugs through the placental barrier is largely determined by the content in uterus. In another words, any decrease of drug content in uterus is able to hinder the placenta transfer process. Recently, Lewis et al. proposed that the dose of Telazol is vital for the residue level in central nervous system and thereby affects the adverse effects exerted on tigers [11]. Analogously, the residue level in uterus is determined by the injected dose of Telazol. In the present case, when the dosage is as low as $5 \mathrm{mg} / \mathrm{kg}$ for tiletamine, a considerably low residue level in uterus will be created in response to the quick elimination, giving rise to the lack capability of placental transfer. On the contrary, the equal injected dose enables the placenta transfer of zolazepam owing to the relatively slow absorption rate. According to these observations, tiletamine in combination with another agent possessing the comparable immobilizing effect of zolazepam but without placental transfer could constitute an ideal option of anesthetic for pregnant mammals. Therefore, our result is expected to be expanded to other anesthetic systems and supervise the anesthesia of pregnant mammals when fetal effect needs to be avoided.

ACKNOWLEDGMENTS. This work is supported by the National Natural Science Foundation of China $(30147358,31272620)$, the Key Project of the Education Department in Sichuan, China (09ZA082, 13ZA0263), and Program for Changjiang Scholars and Innovative Research Team in University (IRT0848).

\section{REFERENCES}

1. Arango-Gonzalez, B., Schatz, A., Bolz, S., Eslava-Schmalbach, J., Willmann, G., Zhour, A., Zrenner, E., Fischer, M. D. and Gekeler, F. 2012. Effects of combined ketamine/xylazine anesthesia on light induced retinal degeneration in rats. PLoS ONE 7: e35687. [Medline] [CrossRef]

2. Baldridge, S. L., Coetzee, J. F., Dritz, S. S., Reinbold, J. B., Gehring, R., Havel, J. and Kukanich, B. 2011. Pharmacokinetics and physiologic effects of intramuscularly administered xylazine hydrochloride-ketamine hydrochloride-butorphanol tartrate alone or in combination with orally administered sodium salicylate on biomarkers of pain in Holstein calves following castration and dehorning. Am. J. Vet. Res. 72: $1305-1317$. [Medline] [CrossRef]

3. Brezina, U., Valenta, H., Rempe, I., Kersten, S., Humpf, H. U. and Dänicke, S. 2014. Development of a liquid chromatography tandem mass spectrometry method for the simultaneous determination of zearalenone, deoxynivalenol and their metabolites in pig serum. Mycotoxin Res. 30: 171-186. [Medline] [CrossRef]

4. Cortínez, L. I., Anderson, B. J., Penna, A., Olivares, L., Muñoz, H. R., Holford, N. H. G., Struys, M. M. and Sepulveda, P. 2010. Influence of obesity on propofol pharmacokinetics: derivation of a pharmacokinetic model. Br. J. Anaesth. 105: 448-456. [Medline] [CrossRef]

5. Fresno, L., Andaluz, A., Moll, X., Cristofol, C., Arboix, M. and García, F. 2008. Placental transfer of etomidate in pregnant ewes after an intravenous bolus dose and continuous infusion. Vet. J. 175: 395-402. [Medline] [CrossRef]

6. Ji, B., Wang, X., Pinto-Duarte, A., Kim, M., Caldwell, S., Young, J. W., Behrens, M. M., Sejnowski, T. J., Geyer, M. A. and Zhou, X. 2013. Prolonged ketamine effects in Sp4 hypomorphic mice: mimicking phenotypes of schizophrenia. PLoS ONE 8: e66327. [Medline] [CrossRef]

7. Kang, W. 2012. Quantitative determination of uridine in rabbit plasma and urine by liquid chromatography coupled to a tandem mass spectrometry. Biomed. Chromatogr. 26: 541-544. [Medline] [CrossRef]

8. Larenza, M. P., Knobloch, M., Landoni, M. F., Levionnois, O. L., Kronen, P. W., Theurillat, R., Schatzmann, U. and Thormann, W. 2008. Stereoselective pharmacokinetics of ketamine and norketamine after racemic ketamine or S-ketamine administration in Shetland ponies sedated with xylazine. Vet. J. 177: 432-435. [Medline] [CrossRef]

9. Laricchiuta, P., De Monte, V., Campolo, M., Grano, F., Crovace, A. and Staffieri, F. 2015. Immobilization of captive tigers (Panthera tigris) with a combination of tiletamine, zolazepam, and detomidine. Zoo Biol. 34: 40-45. [Medline] [CrossRef]

10. Lee, J. Y., Jee, H. C., Jeong, S. M., Park, C. S. and Kim, M. C. 2010. Comparison of anaesthetic and cardiorespiratory effects of xylazine or medetomidine in combination with tiletamine/zolazepam in pigs. Vet. Rec. 167: 245-249. [Medline] [CrossRef]

11. Lewis, J. C. M., Teale, P., Webber, G., Sear, J. W. and Taylor, P. M. 2014. Comparison of tiletamine and zolazepam pharmacokinetics in tigers (Panthera tigris) and leopards (Panthera pardus): do species differences account for adverse effects in tigers? Vet. J. 201: 302-306. [Medline] [CrossRef]

12. Li, P., Han, H., Zhai, X., He, W., Sun, L. and Hou, J. 2012. Simultaneous HPLC-UV determination of ketamine, xylazine, and midazolam in canine plasma. J. Chromatogr. Sci. 50: 108-113. [Medline] [CrossRef]

13. Marzolini, C. and Kim, R. B. 2005. Placental transfer of antiretroviral drugs. Clin. Pharmacol. Ther. 78: 118-122. [Medline] [CrossRef]

14. Myllynen, P., Pasanen, M. and Vahakangas, K. 2007. The fate and effects of xenobiotics in human placenta. Expert. Opin. Drug Metm. 3: 331-346. [CrossRef]

15. Noh, K., Kim, S. Y., Kam, Y. L., Choo, H. Y. P., Lee, H. J. and Kang, W. 2011. Determination of a novel low-voltage-activated calcium channel blocker (HYP-10) in rat plasma by liquid chromatography-mass spectrometry. J. Pharm. Biomed. Anal. 54: 568-571. [Medline] [CrossRef]

16. Sibley, C. P., Coan, P. M., Ferguson-Smith, A. C., Dean, W., Hughes, J., Smith, P., Reik, W., Burton, G. J., Fowden, A. L. and Constância, M. 2004. Placental-specific insulin-like growth factor 2 (Igf2) regulates the diffusional exchange characteristics of the mouse placenta. Proc. Natl. Acad. Sci. U.S.A. 101: 8204-8208. [Medline] [CrossRef]

17. Wagner, A. and Ryan, S. 2006. An in-depth look: cesarean section in dogs: anesthetic management. Comp. Cont. Educ. Pract. $28: 6$. 